\title{
Mine-Impact Burial Model (IMPACT35) Verification and Improvement Using Sediment Bearing Factor Method
}

\author{
Peter C. Chu and Chenwu Fan
}

\begin{abstract}
Recently, a 3-D model (IMPACT35) was developed to predict a falling cylindrical mine's location and orientation in air-water-sediment columns. The model contains the following three components: 1) triple coordinate transform, 2) hydrodynamics of falling rigid object in a single medium (air, water, or sediment) and in multiple media (air-water and water-sediment interfaces), and 3) delta method for sediment resistance with the transient pore pressure. Two mine-impact burial experiments were conducted to detect the mine trajectory in water column [Carderock Division, Naval Surface Warfare Center (NSWC), West Bethesda, MD, on September 10-14, 2001], and to measure the mine burial volume in sediment (Baltic Sea in June 2003). The existing IMPACT35 predicts a mine's location and orientation in the water column, but not in the sediment column. Since sediment resistance largely affects the mine burial depth and orientation in sediment, a new method (bearing factor) is proposed to compute the sediment resistant force and torque. The improvement of IMPACT35 with the bearing factor method is verified using the data collected from the Baltic Sea mine-impact burial experiment. The prediction error satisfies near-Gaussian distribution. The bias of the burial volume (in percent) prediction reduces from $11 \%$ using the delta method (old) to $0.1 \%$ using the bearing factor method (new). Correspondingly, the root-mean-square error (rmse) reduces from $\mathbf{2 6 . 8 \%}$ to $\mathbf{1 5 . 8 \%}$.
\end{abstract}

Index Terms-Bearing factor, burial depth and orientation, drag and lift forces and torques, IMPACT35, mine-impact burial prediction, sediment resistance force and torque, triple coordinate system.

\section{INTRODUCTION}

$\mathbf{T}$ HE conclusion of the cold war culminated with the Union of Soviet Socialist Republics (U.S.S.R.) effectively ceasing to exist under international law on December 31, 1991. This historical event caused the U.S. military and specifically the U.S. Navy and Marine Corp Team to shift tactical emphasis from "blue" water, deep-ocean doctrine to littoral warfare doctrine. This shift changed military responses dealing with a wide range of worldwide regional crises requiring forward sea basing, and expeditionary force landing support.

Manuscript received March 28, 2005; revised May 19, 2006; accepted August 8,2006 . This work was supported by the U.S. Office of Naval Research Marine Geosciences Program N0001403WR20178 and N0001404WR20067, by the Naval Oceanographic Office, and by the Naval Postgraduate School.

Guest Editor: M. D. Richardson.

The authors are with the Naval Ocean Analysis and Prediction Laboratory, Department of Oceanography, Naval Postgraduate School, Monterey, CA 93943 USA (e-mail: pcchu@nps.edu).

Color versions of one or more of the figures in this paper are available online at http://ieeexplore.ieee.org.

Digital Object Identifier 10.1109/JOE.2007.890942
Sea mines are big threat in naval operations. Within the past 15 years three U.S. ships, the U.S.S. Samuel B. Roberts (FFG-58), Tripoli (LPH-10), and Princeton (CG-59) have fallen victim to mines. Total ship damage was $\$ 125$ million while the mines cost approximately $\$ 30000$ [1]. Mines have evolved over the years from the dumb "horned" contact mines that damaged the Tripoli and Roberts to ones that are relatively sophisticated-nonmagnetic materials, irregular shapes, anechoic coatings, multiple sensors, and ship count routines. Despite their increased sophistication, mines remain inexpensive and are relatively easy to manufacture, keep, and place.

Accurate mine burial predictions are inherently difficult [2], because of unknown conditions in mine deployment and uncertain environments such as waves, currents, and sediment transports [3]. The U.S. Navy developed operational models to forecast ocean environments for mine burial prediction [4], [5]. Recently, statistical methods such as the Monte Carlo [6] and the expert system methods [3] have been developed. These methods have a core-physical model for falling rigid body through air-water-sediment columns. The U.S. Navy has a 2-D model (IMPACT28) to predict a cylinder's trajectory and impact burial. The data collected from the mine-impact burial experiment in the surf zone near the Naval Postgraduate School, Monterey, CA, shows overprediction of the burial depth (an order of magnitude larger) using IMPACT28 [7].

A 3-D model (IMPACT35) was recently developed at the Naval Postgraduate School to predict a cylinder's trajectory and impact burial [8]-[12]. The dynamical system can be simplified using the following three coordinate systems: earth-fixed coordinate (E-coordinate), the cylinder's main-axis-following coordinate (M-coordinate), and hydrodynamic force-following coordinate (F-coordinate). The origin of both $\mathrm{M}$ - and F-coordinates is at the cylinder's center of mass (COM). The body forces and their moments are easily calculated using the E-coordinate system. The hydrodynamic forces and their moments are easily computed using the F-coordinate. The cylinder's moments of gyration are simply represented using the M-coordinate. When the mine penetrates into an interface between two media (air-water or water-sediment), the cylinder is decomposed into two parts with each one contacting one medium. The body forces (such as the buoyancy force) and surface forces (such as pressure, hydrodynamic force) are computed separately for the two parts. A fully 3-D model is developed for predicting the translation velocity and orientation of a falling cylindrical mine through air, water, and sediment. The added value capability of the 3-D model (IMPACT35) versus the 2-D model (IMPACT28) is verified using experimental data. 


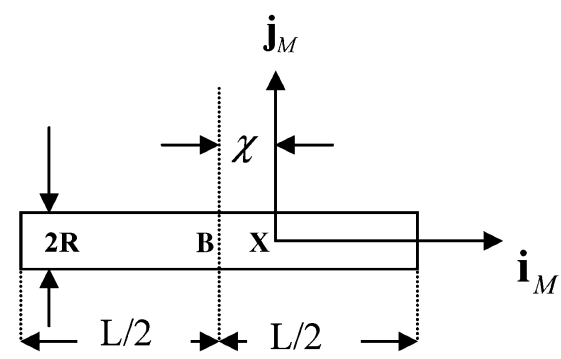

Fig. 1. M-coordinate with the COM as the origin $\mathbf{X}$ and $\left(i_{m}, j_{m}\right)$ as the two axes. Here, $\chi$ is the distance between the $\operatorname{COV}(\mathbf{B})$ and $\operatorname{COM}(\mathbf{X}) ;(L, R)$ are the cylinder's length and radius [8].

Recently, two mine-impact burial experiments were conducted to detect mine trajectory in the water column [Carderock Division, Naval Surface Warfare Center (NSWC), West Bethesda, MD, on September 10-14, 2001] and to measure the mine burial in the sediment (Baltic Sea in June 2003). The collected data are used for model verification. Section II describes basic physics of the recently developed 3-D model (IMPACT35). Section III shows the added value of IMPACT35 in predicting mine movement in the water column. However, Section IV shows weakness of the existing IMPACT35 in predicting mine movement in sediment. Section $\mathrm{V}$ presents the new bearing factor method to compute the sediment resistant force and torque. Section VI shows the improvement of the bearing factor method in predicting mine burial in sediment. Section VII presents the conclusions.

\section{DESCRIPTION OF IMPACT35}

The 3-D mine-impact burial prediction model (IMPACT35) contains the following major components: 1) triple coordinate systems, 2) momentum balance, 3) moment of momentum balance, 4) hydrodynamics, and 5) sediment dynamics. Among them, the hydrodynamics (drag and lift forces and torques) have been described in [8] and [11]-[13], and will not be discussed here.

\section{A. Triple Coordinate Systems}

Consider an axially symmetric cylinder with the center of mass (COM) $\mathbf{X}$ and the center of volume (COV) $\mathbf{B}$ on the main axis (Fig. 1). Let $(L, R, \chi)$ represent the cylinder's length, radius, and the distance between the two points $(\mathbf{X}, \mathbf{B})$. The positive $\chi$-values refer to the nose-down case, i.e., the point $\mathbf{X}$ is lower than the point $\mathbf{B}$. Three coordinate systems are used to model the falling cylinder through the air, water, and sediment phases: earth-fixed coordinate (E-coordinate), main-axisfollowing coordinate (M-coordinate), and force-following coordinate (F-coordinate) systems. All the systems are 3-D, orthogonal, and right-handed [8].

The E-coordinate system is represented by $F_{E}(O, \mathbf{i}, \mathbf{j}, \mathbf{k})$ with the origin $O$, and three axes: $x$ - and $y$-axes (horizontal) with the unit vectors $(\mathbf{i}, \mathbf{j})$ and $z$-axis (vertical) with the unit vector $\mathbf{k}$ (upward positive). The position of the cylinder is represented by the position of the $\mathrm{COM}$

$$
\mathbf{X}=x \mathbf{i}+y \mathbf{j}+z \mathbf{k}
$$
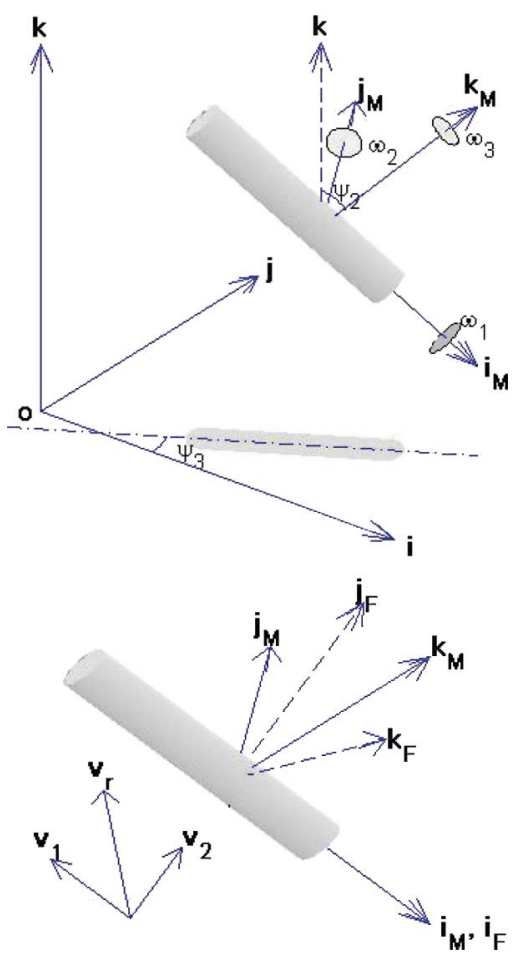

Fig. 2. Three coordinate systems. Here, $(\mathbf{i}, \mathbf{j}, \mathbf{k})$ are the unit vectors of E-coordinate system. Both M- and F-coordinate systems share the same axis, i.e., $\mathbf{i}_{M}$ and $\mathbf{i}_{F}$ are the same unit vectors [8].

which describes translation of the cylinder. The translation velocity is given by

$$
\frac{d \mathbf{X}}{d t}=\mathbf{V}, \quad \mathbf{V}=(u, v, w) .
$$

Let the orientation of the cylinder's main axis (pointing downward) be given by $\mathbf{i}_{M}$. The angle between $\mathbf{i}_{M}$ and $\mathbf{k}$ is denoted by $\psi_{2}+\pi / 2$. Projection of the vector $\mathbf{i}_{M}$ onto the $(x, y)$-plane creates angle $\left(\psi_{3}\right)$ between the projection and the $x$-axis (Fig. 2). The M-coordinate system is represented by $F_{M}\left(\mathbf{X}, \mathbf{i}_{M}, \mathbf{j}_{M}, \mathbf{k}_{M}\right)$ with the origin $\mathbf{X}$, unit vectors $\left(\mathbf{i}_{M}, \mathbf{j}_{M}, \mathbf{k}_{M}\right)$, and coordinates $\left(x_{M}, y_{M}, z_{M}\right)$. In the plane consisting of vectors $\mathbf{i}_{M}$ and $\mathbf{k}$ (passing through the point $M$ ), two new unit vectors $\left(\mathbf{j}_{M}, \mathbf{k}_{M}\right)$ are defined with $\mathbf{j}_{M}$ perpendicular to the $\left(\mathbf{i}_{M}, \mathbf{k}\right)$-plane, and $\mathbf{k}_{M}$ perpendicular to $\mathbf{i}_{M}$ in the $\left(\mathbf{i}_{M}, \mathbf{k}\right)$-plane. The unit vectors of the M-coordinate system are given by (Fig. 2)

$$
\mathbf{j}_{M}=\mathbf{k}_{M} \times \mathbf{i}_{M}, \quad \mathbf{k}_{M}=\mathbf{i}_{M} \times \mathbf{j}_{M} .
$$

The M-coordinate system is solely determined by the orientation of the cylinder's main axis $\mathbf{i}_{M}$.

The F-coordinate system is represented by $F_{F}\left(\mathbf{X}, \mathbf{i}_{F}, \mathbf{j}_{F}, \mathbf{k}_{F}\right)$ with the origin $\mathbf{X}$, unit vectors $\left(\mathbf{i}_{F}, \mathbf{j}_{F}, \mathbf{k}_{F}\right)$, and coordinates $\left(x_{F}, y_{F}, z_{F}\right)$. Let $\mathbf{V}_{w}$ be the fluid velocity. The fluid-to-cylinder velocity is represented by $\mathbf{V}_{r}=\mathbf{V}_{w}-\mathbf{V}$, that is decomposed into two parts

$$
\mathbf{V}_{r}=\mathbf{V}_{1}+\mathbf{V}_{2}, \quad \mathbf{V}_{1}=V_{1} \mathbf{i}_{F}, \quad \mathbf{V}_{2}=V_{2} \mathbf{j}_{F}
$$

where

$$
\mathbf{V}_{1}=\left(\mathbf{V}_{r} \cdot \mathbf{i}_{F}\right) \mathbf{i}_{F}
$$


TABLE I

PhySicAl PARAMETERS OF THE MODEl Mines IN THE NSWC-CARDEROCK EXPERIMENT (AFTER [19])

\begin{tabular}{|c|l|c|c|c|c|c|}
\hline Mine & $\begin{array}{l}\text { Mass } \\
(\mathrm{kg})\end{array}$ & $\begin{array}{c}\rho \\
\left(10^{3} \mathrm{~kg} \mathrm{~m}^{-3}\right)\end{array}$ & $\begin{array}{l}L \\
(\mathrm{~m})\end{array}$ & $\begin{array}{l}J_{1} \\
\left(\mathrm{~kg} \mathrm{~m}^{2}\right)\end{array}$ & $\begin{array}{l}J_{2}\left(J_{3}\right) \\
\left(\mathrm{kg} \mathrm{m}^{2}\right)\end{array}$ & $\begin{array}{l}\chi \\
(\mathrm{m})\end{array}$ \\
\hline 1 & 16.96 & 1.60 & 0.505 & 0.0647 & 0.356 & 0 \\
\hline 2 & 22.27 & 2.10 & 0.505 & 0.0806 & 0.477 & 0 \\
\hline 3 & 34.93 & 1.60 & 1.010 & 0.1362 & 2.900 & 0 \\
\hline 4 & 45.85 & 2.10 & 1.010 & 0.1696 & 3.820 & 0 \\
\hline 5 & 45.85 & 2.10 & 1.010 & 0.1693 & 3.940 & 0.0045 \\
\hline 6 & 45.85 & 2.10 & 1.010 & 0.1692 & 4.570 & -0.077 \\
\hline
\end{tabular}

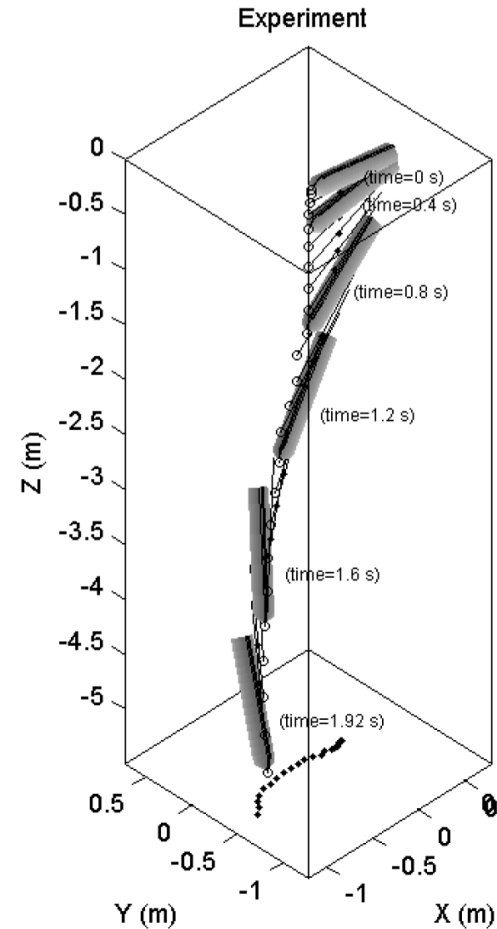

(a)

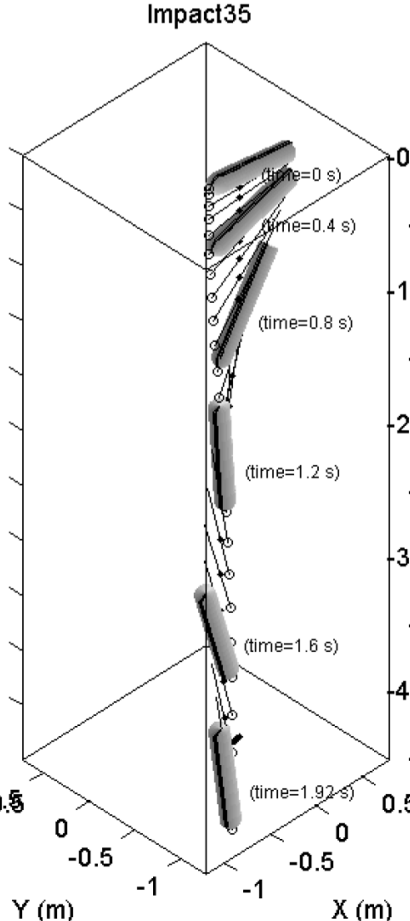

(b)

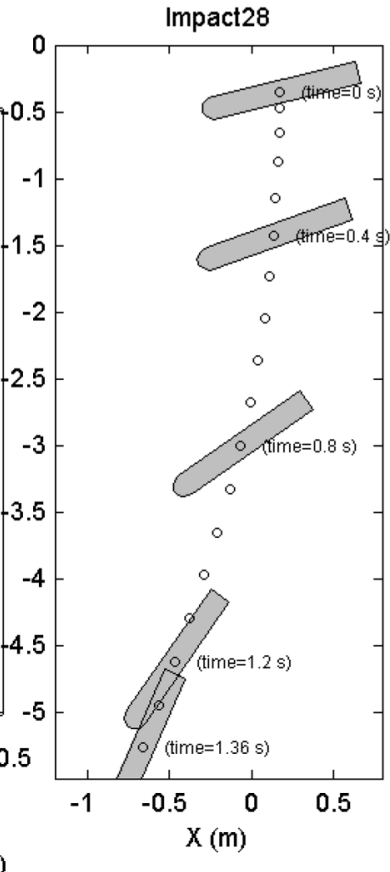

(c)

Fig. 3. Movement of mine \#6 ( $L=1.01 \mathrm{~m}, \rho=2.1 \times 10^{3} \mathrm{~kg} \mathrm{~m}^{-3}$ ) with $\chi=-0.0077 \mathrm{~m}$ and $\psi_{2}=-14.0^{\circ}$ obtained from (a) NSWC-Carderock experiment, (b) 3-D IMPACT35 model, and (c) 2-D IMPACT28 model (after [11]).

is the component paralleling to the cylinder's main axis (i.e., along $\mathbf{i}_{M}$ ), and

$$
\mathbf{V}_{2}=\mathbf{V}_{r}-\left(\mathbf{V}_{r} \cdot \mathbf{i}_{F}\right) \mathbf{i}_{F}
$$

is the component perpendicular to the cylinder's main axial direction. The unit vectors for the F-coordinate are defined by (column vectors)

$$
\mathbf{i}_{F}=\mathbf{i}_{M}=\left[\begin{array}{l}
r_{11} \\
r_{21} \\
r_{31}
\end{array}\right], \quad \mathbf{j}_{F}=\mathbf{V}_{2} /\left|\mathbf{V}_{2}\right|, \quad \mathbf{k}_{F}=\mathbf{i}_{F} \times \mathbf{j}_{F} .
$$

The F-coordinate system is solely determined by the orientation of the cylinder's main axis $\left(\mathbf{i}_{M}\right)$ and the water-to-cylinder velocity. Note that the M- and F-coordinate systems have one common unit vector $\mathbf{i}_{M}$ (orientation of the cylinder). Use of the F-coordinate system simplifies the calculations for the lift and drag forces and torques acting on the cylinder.

\section{B. Momentum Balance}

The 3-D translation velocity of the cylinder $(\mathbf{V})$ is governed by the momentum equation in the E-coordinate system [8],
[11]-[13]

$$
\frac{d}{d t}\left[\begin{array}{l}
u \\
v \\
w
\end{array}\right]=-\left[\begin{array}{l}
0 \\
0 \\
g
\end{array}\right]+\frac{\mathbf{F}_{n h}+\mathbf{F}_{h}}{\rho \Pi}
$$

where $g$ is the gravitational acceleration, $\Pi$ is the cylinder volume, $\rho$ is the rigid body density, $\rho \Pi=m$ is the cylinder mass, $\mathbf{F}_{n h}$ is the nonhydrodynamic force defined later, and $\mathbf{F}_{h}$ is the hydrodynamic force (i.e., surface force including drag, lift forces). Both $\mathbf{F}_{n h}$ and $\mathbf{F}_{h}$ are integrated for the cylinder. The drag and lift forces are calculated using the drag and lift laws with the given water-to-cylinder velocity $\left(\mathbf{V}_{r}\right)$. In the F-coordinate, $\mathbf{V}_{r}$ is decomposed into along-cylinder $\left(\mathbf{V}_{1}\right)$ and across-cylinder $\left(\mathbf{V}_{2}\right)$ components. The nonhydrodynamic force $\mathbf{F}_{n h}$ is the buoyancy force $\left(\mathbf{F}_{b}\right)$ for the air and water phases

$$
\mathbf{F}_{n h}=\mathbf{F}_{b}=\mathbf{k}\left(\rho_{a} \Pi g, \rho_{w} \Pi g\right)
$$

where $\left(\rho_{a}, \rho_{w}\right)$ are the air and water densities and $\mathbf{F}_{n h}$ is the resultant of buoyancy force $\left(\mathbf{F}_{b}\right)$, and shearing resistance force $\left(\mathbf{F}_{s}\right)$ for the sediment phase. 


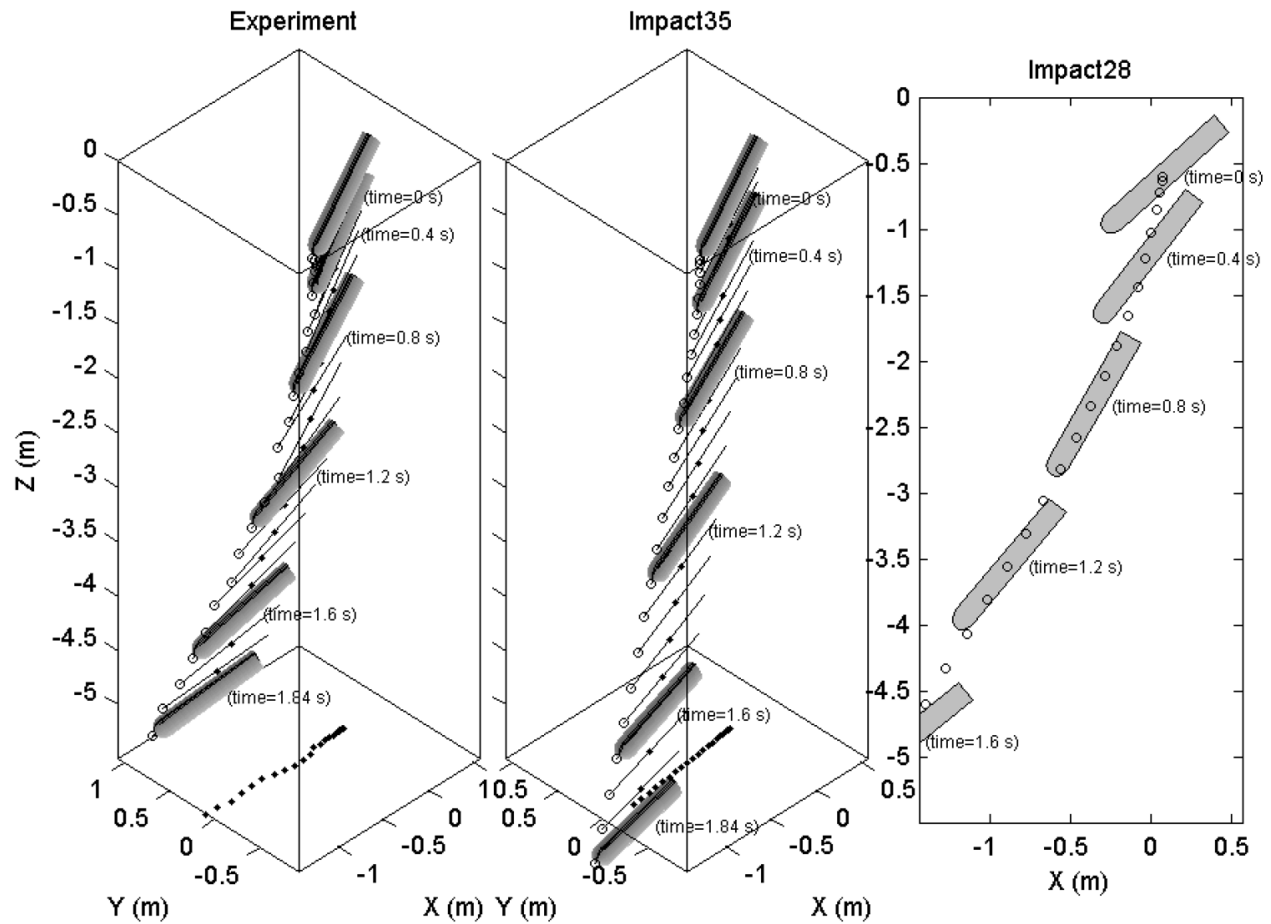

(a)

(b)

(c)

Fig. 4. Movement of mine \#5 ( $L=1.01 \mathrm{~m}, \rho=2.1 \times 10^{3} \mathrm{~kg} \mathrm{~m}^{-3}$ ) with $\chi=0.0045 \mathrm{~m}$ and $\psi_{2}=42.2^{\circ}$ obtained from (a) NSWC-Carderock experiment, (b) 3-D IMPACT35 model, and (c) 2-D IMPACT28 model.

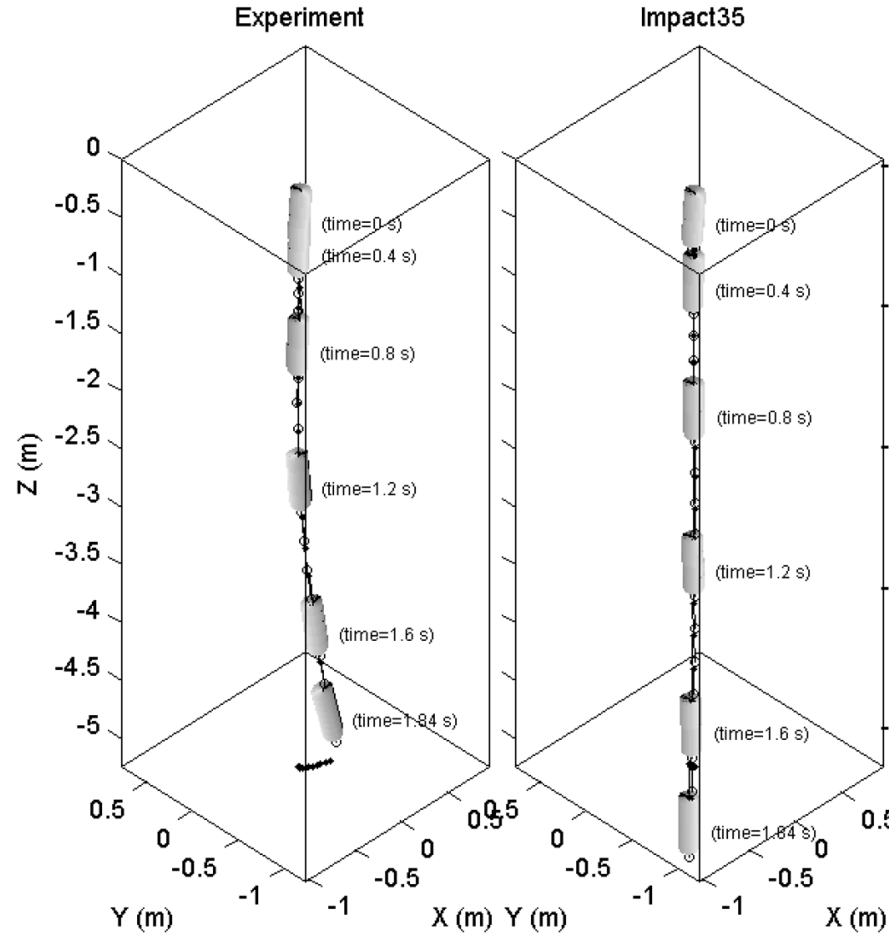

(a) (b)



(c)

Fig. 5. Movement of mine \#2( $\left.L=0.505 \mathrm{~m}, \rho=2.1 \times 10^{3} \mathrm{~kg} \mathrm{~m}^{-3}\right)$ with $\chi=0$ and $\psi_{2}=87.0^{\circ}$ obtained from (a) NSWC-Carderock experiment, (b) 3-D IMPACT35 model, and (c) 2-D IMPACT28 model (after [11]).

\section{Moment of Momentum Equation}

The moment of momentum equation is written in the M-coordinate system, which rotates with the angular velocity of

$$
\boldsymbol{\Omega}=\omega_{2} \mathbf{j}_{M}+\omega_{3} \mathbf{k}_{M} .
$$

Usually, the angular velocity around the mine's main axis $\mathbf{i}_{M}$ (i.e., self-spinning velocity) is very small $\left(\omega_{1} \simeq 0\right)$ and neglected. Thus, we have

$$
\boldsymbol{\Omega}=\boldsymbol{\omega}
$$

This leads to zero centripetal and "Coriolis" terms

$$
\boldsymbol{\Omega} \times(\boldsymbol{\Omega} \times \boldsymbol{\omega})=0, \quad-2 \mathbf{J} \bullet(\boldsymbol{\Omega} \times \boldsymbol{\omega})=0 .
$$



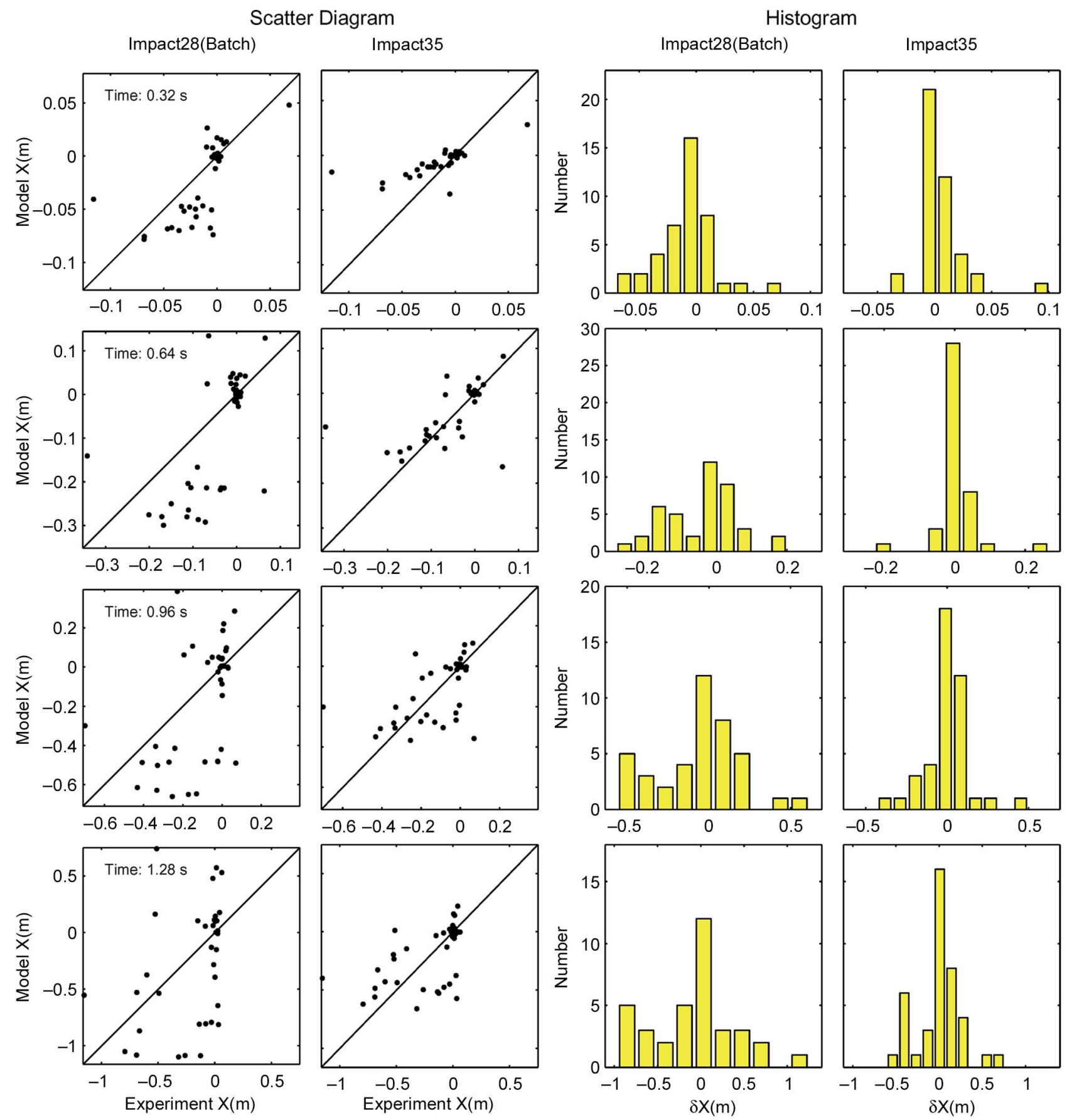

Fig. 6. Model verification from prediction of the COM position $x$ using the NSWC-Carderock experiment data at several time instances: 0.32, 0.64, 0.96, and $1.28 \mathrm{~s}$. Here, the first column is the data-IMPACT28 comparison, the second column is the data-IMPACT35 comparison, the third column shows the histograms of the model error $(\delta x)$ for IMPACT28, and the fourth column shows the histograms of the model error $(\delta x)$ for IMPACT35.

The inertial term

$$
\frac{d \boldsymbol{\Omega}}{d t} \times \boldsymbol{\omega}=\mathbf{i}_{M}\left(\omega_{3} \frac{d \omega_{2}}{d t}-\omega_{2} \frac{d \omega_{3}}{d t}\right)
$$

only has the component along the direction of $\mathbf{i}_{M}$ (mine's main axis). This term may be neglected when the self-spinning ve- locity is small. The moment of momentum equation in the M-coordinate system can be simplified by

$$
\mathbf{J} \bullet \frac{d \boldsymbol{\omega}}{d t} \simeq \mathbf{M}_{n h}+\mathbf{M}_{h}
$$

where $\mathbf{M}_{n h}$ and $\mathbf{M}_{h}$ are the nonhydrodynamic and hydrodynamic force torques. In the M-coordinate system, the moment 

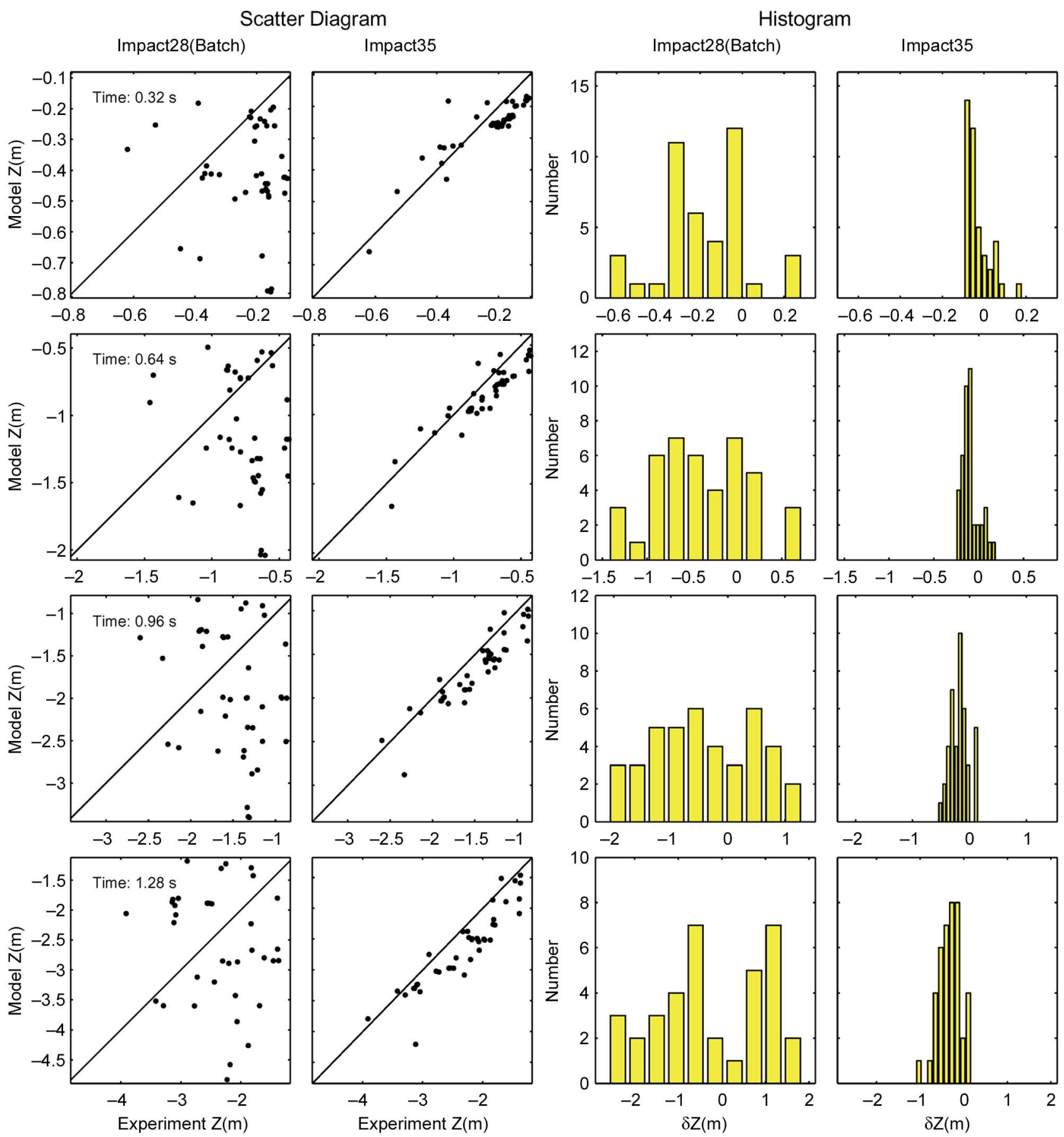

Fig. 7. Model verification from prediction of the COM position $z$ using the NSWC-Carderock experiment data at several time instances: $0.32,0.64,0.96$, and $1.28 \mathrm{~s}$. Here, the first column is the data-IMPACT28 comparison, the second column is the data-IMPACT35 comparison, the third column shows the histograms of the model error $(\delta x)$ for IMPACT28, and the fourth column shows the histograms of the model error $(\delta x)$ for IMPACT35.

of gyration tensor for the axially symmetric cylinder is a diagonal matrix

$$
\mathbf{J}=\left[\begin{array}{ccc}
J_{1} & 0 & 0 \\
0 & J_{2} & 0 \\
0 & 0 & J_{3}
\end{array}\right]
$$

where $J_{1}, J_{2}$, and $J_{3}$ are the moments of inertia. The nonhydrodynamic force usually contains the gravity and buoyancy forces.
The gravity force, passing the COM, does not induce the moment. The buoyancy force induces the moment in the $\mathbf{j}_{M}$ direction if the COM does not coincide with the $\operatorname{COV}$ (i.e., $\chi \neq 0$ )

$$
\mathbf{M}_{b}=\left|\mathbf{F}_{b}\right| \chi \cos \psi_{2} \mathbf{j}_{M} .
$$

\section{Sediment Dynamics}

In the existing IMPACT35 model, the sediment resistance is calculated using the delta method. This method is based on the 


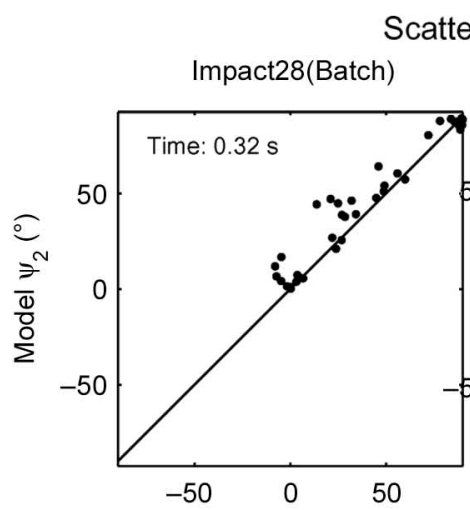

Scatter Diagram
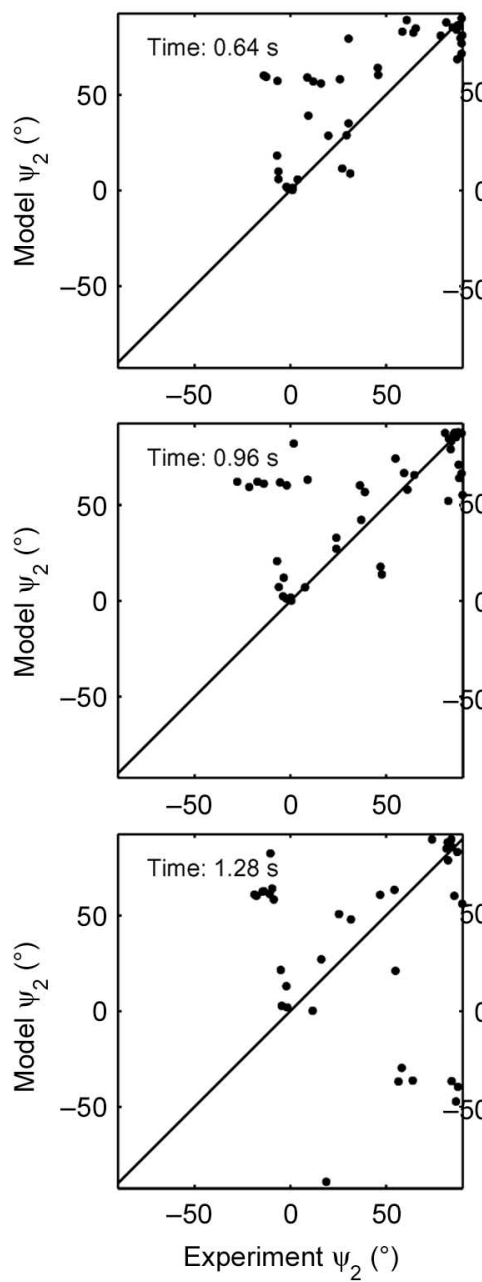

Impact35
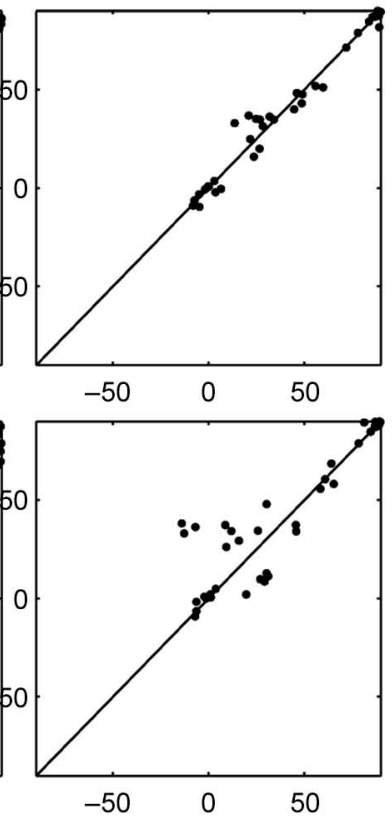
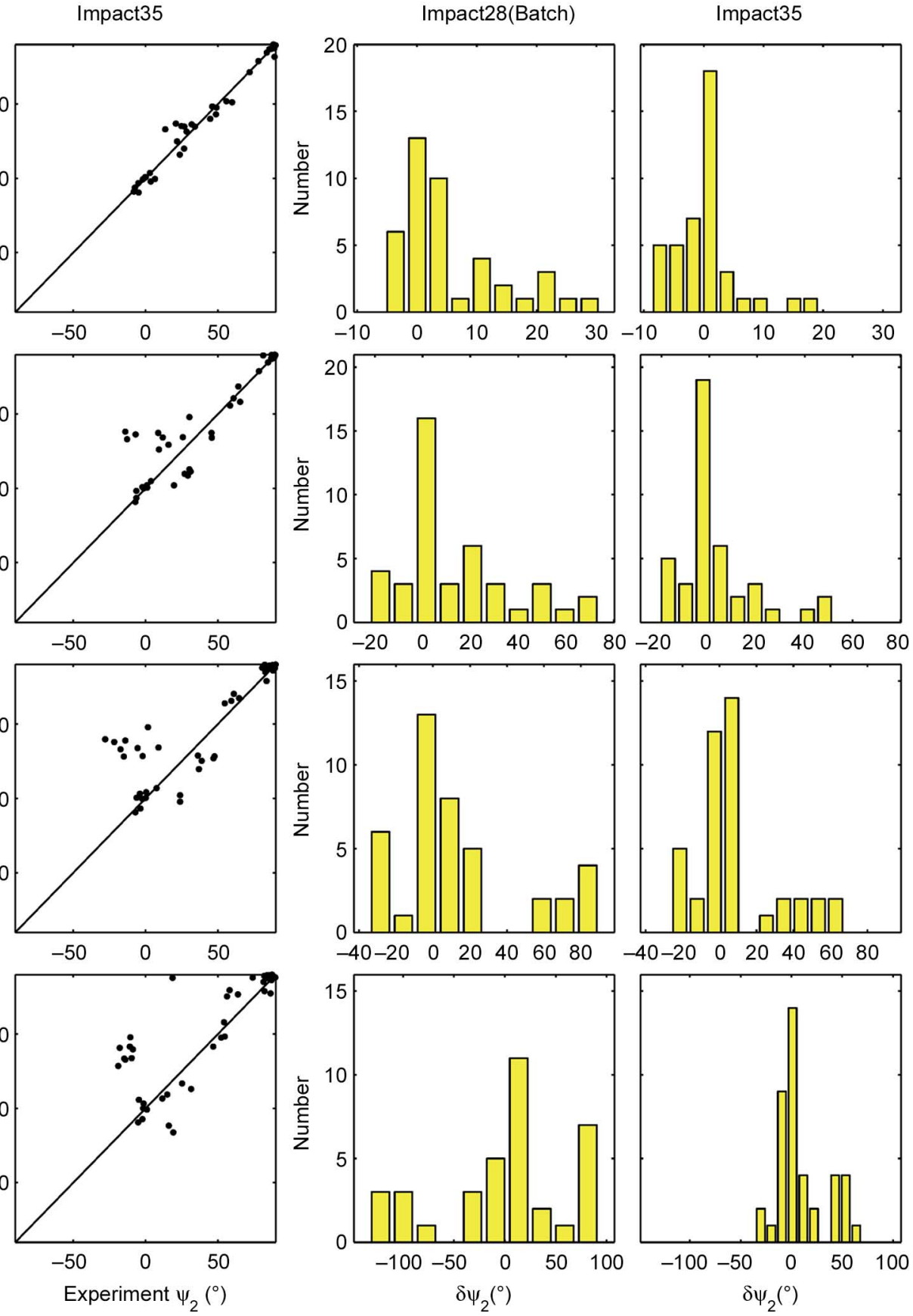

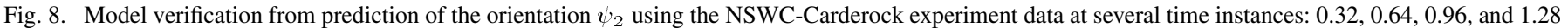

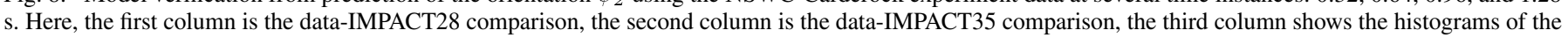
model error $\left(\delta \psi_{2}\right)$ for IMPACT28, and the fourth column shows the histograms of the model error $\left(\delta \psi_{2}\right)$ for IMPACT35.

assumption that the cylinder pushes the sediment and leaves space in the wake as it impacts and penetrates into the sediment. This space is refilled by water and the water cavity is produced. At the instant of penetration, the total resistant force on the cylinder is represented by [16]-[18]

$$
\mathbf{F}^{s}=\int_{\sigma_{\mathrm{sed}}}\left[\delta\left(\mathbf{f}_{b}^{s}+\mathbf{f}_{s h}\right)+\mathbf{f}_{b}^{w}+\mathbf{f}_{h}^{w}\right] d \sigma+\mathbf{F}_{p w}
$$

where $\left(\mathbf{f}_{b}^{s}, \mathbf{f}_{s h}\right)$ and $\left(\mathbf{f}_{b}^{w}, \mathbf{f}_{h}^{w}\right)$ are the sediment buoyancy and shear resistance forces and water buoyancy and hydrody- namic forces (per unit area) at the point $\mathbf{r}$ over the cylinder's surface, $\sigma_{\text {sed }}$ is the area of the cylinder's surface below the water-sediment interface, $\mathbf{F}_{p w}$ is the pore water pressure force on the whole cylinder, and $\delta$-function is defined by

$$
\delta= \begin{cases}1 & \mathbf{v} \bullet \mathbf{n} \geq 0 \\ 0 & \mathbf{v} \bullet \mathbf{n} \leq 0\end{cases}
$$

which shows that the sediment buoyancy and shear resistance forces act when the cylinder moves towards them. Here, $\mathbf{v}$ is 

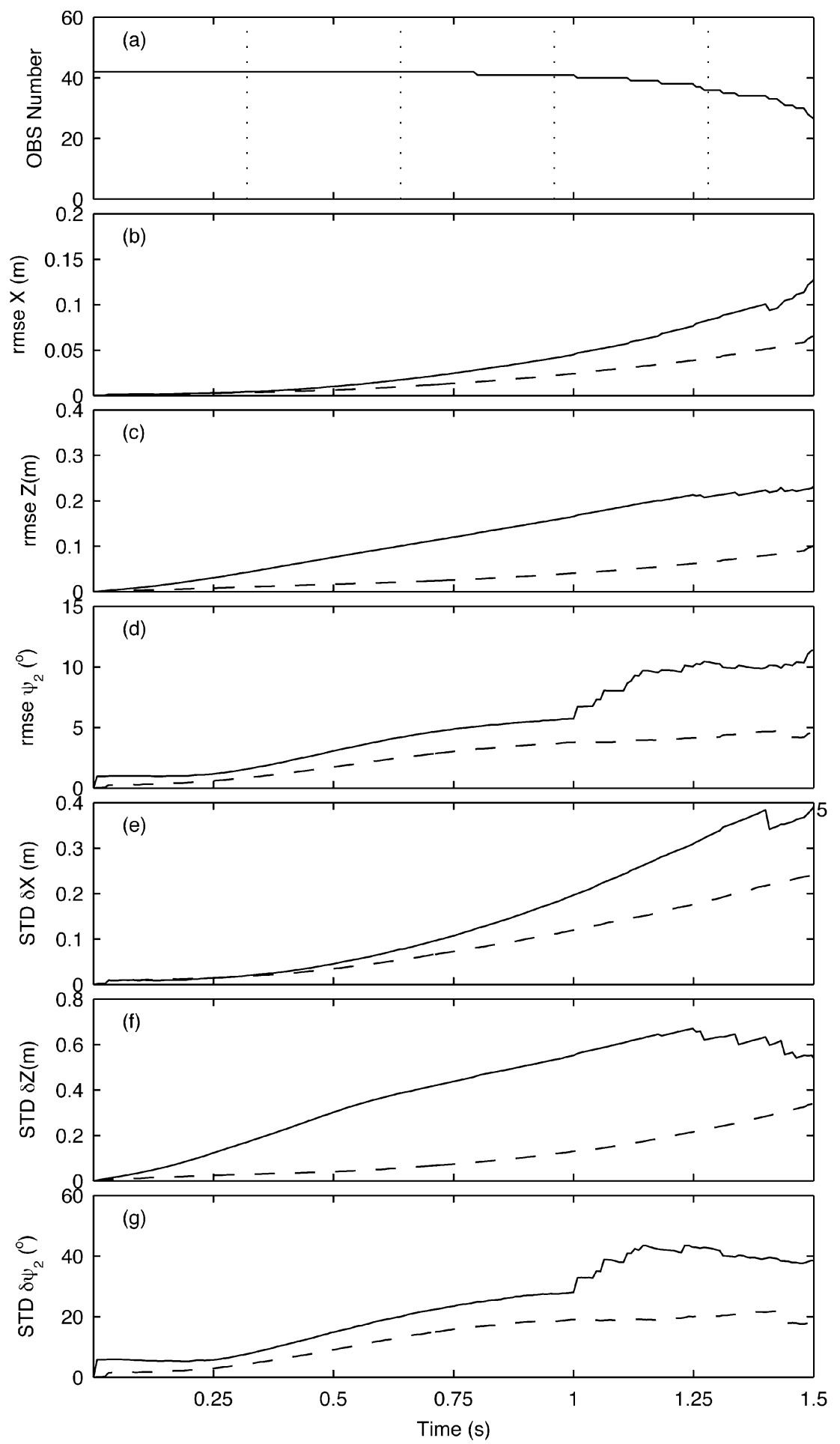

Fig. 9. Temporal evolution of model performance evaluated using the NSWC-Carderock data: (a) observational data number, (b) rmse of $x$, (c) rmse of $z$, (d) rmse of $\psi_{2}$, (e) STD of $\delta x$, (f) STD of $\delta z$, and (g) STD of $\delta \psi_{2}$ with the solid curves for IMPACT28 and dashed curves for IMPACT35 from (b) to (g).

the velocity at point $\mathbf{r}$ (represented in the M-coordinate) on the cylinder surface

$$
\mathbf{v}=\mathbf{V}+\boldsymbol{\omega} \times \mathbf{r}
$$

\section{VERIFICATION OF IMPACT35 IN THE WATER COLUMN}

The NSWC-Carderock experiment was conducted on September 10-14, 2001 in the Explosion Test Pond, which is the only explosive-related test pond in the United States with the capability of providing high-speed underwater photography given its exceptional water clarity. In addition, the facility's concrete floor thickness and reinforcement is sufficient to allow impact of 45-kg cylinders without additional floor protection. The pond in plan view is a regular pentagon with each side of $41 \mathrm{~m}$. During the experiment, six model mines (Table I) with mass varying from 16.96 to $45.85 \mathrm{~kg}$ were released to the pond 


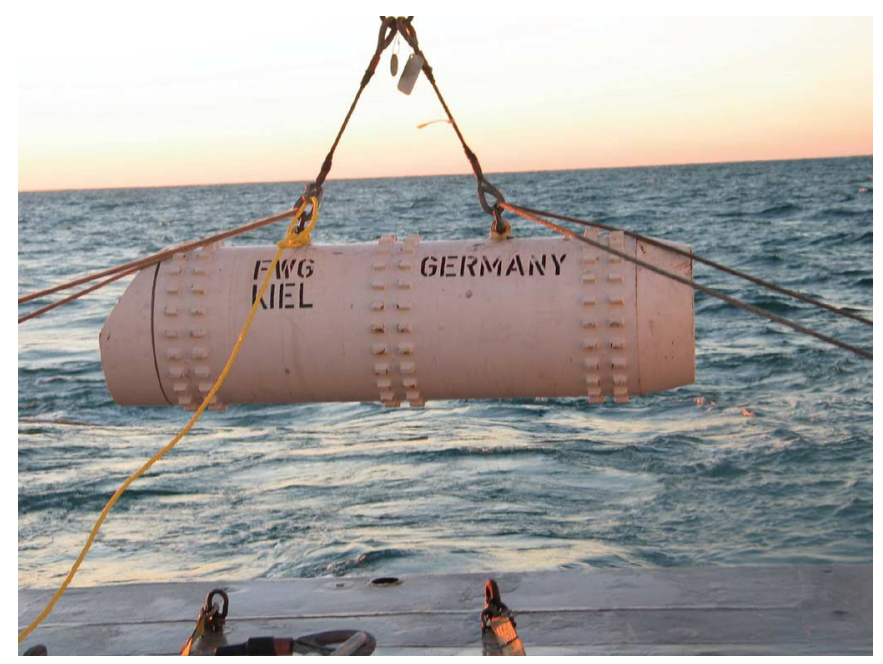

Fig. 10. Optical mine used in the Baltic Sea experiment (after [24]).

TABLE II

Physical Parameters of THE Full-Size Optical Mine IN THE BALTIC SEA EXPERIMENT (AFTER [24])

\begin{tabular}{ll}
\hline Length $(\mathrm{m})$ & 1.466 \\
\hline Diameter $(\mathrm{m})$ & 0.470 \\
Taper Diameter $(\mathrm{m})$ & 0.395 \\
Taper Length $(\mathrm{m})$ & 0.150 \\
Volume $\left(\mathrm{m}^{3}\right)$ & 0.252 \\
Mass $(\mathrm{kg})$ & 550.00 \\
$\chi(\mathrm{m})$ & 0 \\
$\mathrm{~J}_{1}\left(\mathrm{~kg} \mathrm{~m}^{2}\right)$ & 14.82 \\
\hline $\mathrm{J}_{2}, \mathrm{~J}_{3}\left(\mathrm{~kg} \mathrm{~m}^{2}\right)$ & 105.00 \\
\hline
\end{tabular}

TABLE III

Physical PARAMETERS OF THE ENVIRONMENT IN THE BALTIC SEA EXPERIMENT (AFTER [24])

\begin{tabular}{ll}
\hline Air Density $\left(\mathrm{kg} \mathrm{m}^{-3}\right)$ & 1.22 \\
\hline Water Density $\left(\mathrm{kg} \mathrm{m}^{-3}\right)$ & 1025.8 \\
Air Kinetic Viscosity $\left(\mathrm{m}^{2} \mathrm{~s}^{-1}\right)$ & $1.46 \times 10^{-5}$ \\
\hline Water Kinetic Viscosity $\left(\mathrm{m}^{2} \mathrm{~s}^{-1}\right)$ & $1.13 \times 10^{-6}$ \\
\hline
\end{tabular}

with the water depth at $7.92 \mathrm{~m} \mathrm{[19],} \mathrm{[20].} \mathrm{The} \mathrm{data} \mathrm{set} \mathrm{collected}$ from the NSWC-Carderock experiment was used to evaluate the added value of IMPACT35 versus IMPACT28 (2-D model).

\section{A. Near Horizontal Release}

Model mine \#6 was released to the water with $\psi_{2}=-14^{\circ}$ (near horizontal, see Fig. 2). The physical parameters of this mine are given by

$$
\begin{aligned}
L & =1.01 \mathrm{~m}, \quad \rho=2.10 \times 10^{3} \mathrm{~kg} \mathrm{~m}^{-3}, \quad \chi=-0.077 \mathrm{~m}, \\
m & =45.85 \mathrm{~kg}, \quad J_{1}=0.1692 \mathrm{~kg} \mathrm{~m}^{2}, \quad J_{2}=J_{3}=4.570 \mathrm{~kg} \mathrm{~m}^{2} .
\end{aligned}
$$

The initial conditions are given by

$$
\begin{aligned}
x_{0} & =y_{0}=z_{0}=0, \quad u_{0}=v_{0}=w_{0}=0, \\
r \psi_{10} & =0, \quad \psi_{20}=-14^{\circ}, \quad \psi_{30}=0, \quad \omega_{10}=\omega_{20}=\omega_{30}=0 .
\end{aligned}
$$

Substitution of the model parameters (17) and the initial conditions (18) into IMPACT28 and IMPACT35 leads to the prediction of the mine's translation and orientation that are compared with the data collected during the experiment at each time step (Fig. 3). The new 3-D model (IMPACT35) simulated trajectory agrees well with the observed trajectory. Both show the same pattern and the same travel time (1.92 s) for the cylinder passing through the water column. However, the 3-D model (IMPACT35) is better than the 2-D model (IMPACT28) in predicting the mine's movement in the water column.

\section{B. Near $45^{\circ}$ Release}

Model mine \#6 was released to the water with $\psi_{2}=42.2^{\circ}$. The initial conditions are given by

$$
\begin{aligned}
x_{0} & =y_{0}=z_{0}=0, \quad u_{0}=v_{0}=w_{0}=0 \\
\psi_{10} & =0, \quad \psi_{20}=42.2^{\circ}, \quad \psi_{30}=0, \quad \omega_{10}=\omega_{20}=\omega_{30}=0 .
\end{aligned}
$$

Substitution of the model parameters (17) and the initial conditions (19) into IMPACT28 and IMPACT35 leads to the prediction of the mine's translation and orientation that are compared with the data collected during the experiment at time steps (Fig. 4). Both 3-D model (IMPACT35) and 2-D model (IMPACT28) simulated trajectories and travel times agree well with the observed trajectory.

\section{Near Vertical Release}

Model mine \#2 was released to the water with $\psi_{2}=87^{\circ}$. The physical parameters of this mine are given by

$$
\begin{aligned}
L & =0.505 \mathrm{~m}, \quad \rho=2.10 \times 10^{3} \mathrm{~kg} \mathrm{~m}^{-3}, \quad \chi=0, \\
m & =22.27 \mathrm{~kg}, \quad J_{1}=0.0806 \mathrm{~kg} \mathrm{~m}^{2}, \\
J_{2} & =J_{3}=0.477 \mathrm{~kg} \mathrm{~m}^{2} .
\end{aligned}
$$

The initial conditions are given by

$$
\begin{aligned}
x_{0} & =y_{0}=z_{0}=0, \quad u_{0}=v_{0}=w_{0}=0, \\
\psi_{10} & =0, \quad \psi_{20}=87^{\circ}, \quad \psi_{30}=0, \quad \omega_{10}=\omega_{20}=\omega_{30}=0 .
\end{aligned}
$$

The predicted cylinder's translation and orientation are compared with the data collected at time steps (Fig. 5). The 3-D model (IMPACT35) simulated trajectory agrees well with the observed trajectory. Both show the same straight pattern and the same travel time $(1.84 \mathrm{~s})$ for the cylinder passing through the water column.

\section{Statistical Error Analysis}

Figs. 6-8 show scatter diagrams and histograms for predicting the mine's location and orientation $\left[x(t), z(t), \psi_{2}(t)\right]$. In the scatter diagrams, the points cluster around the diagonal line of $\varsigma_{m}=\varsigma_{o}$ using IMPACT35 (second column), and the points are spreading out of the diagonal line using IMPACT28 (first column), which confirms that IMPACT35 predicts COM position more accurately than IMPACT28. Histograms of model errors for COM position have Gaussian-type distribution 
(a)

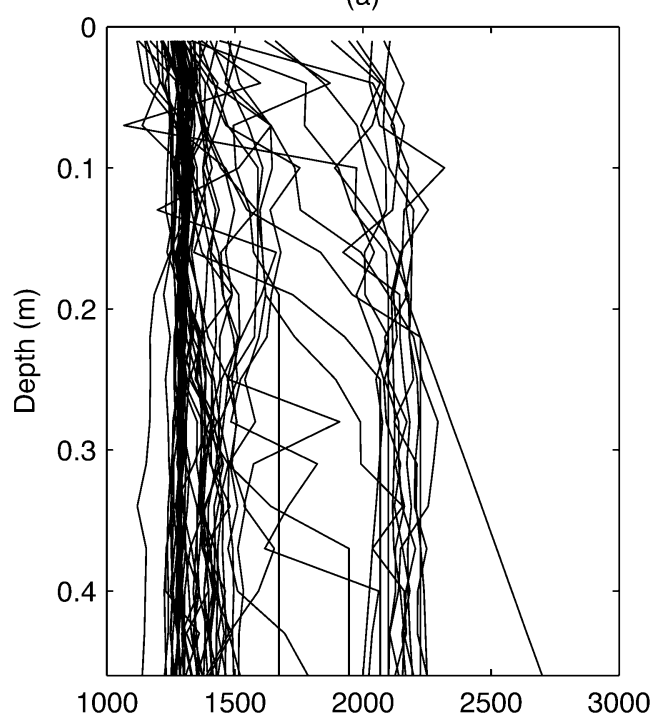

(c)

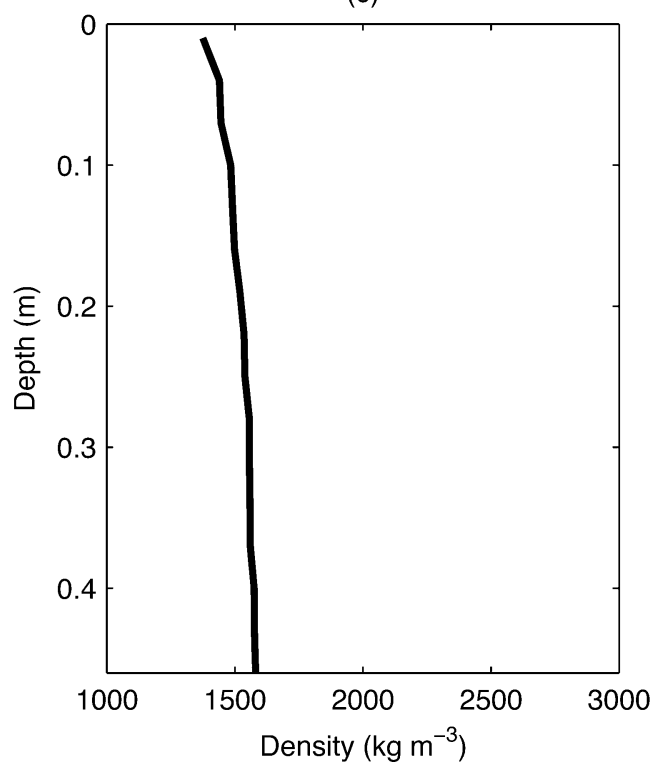

(b)

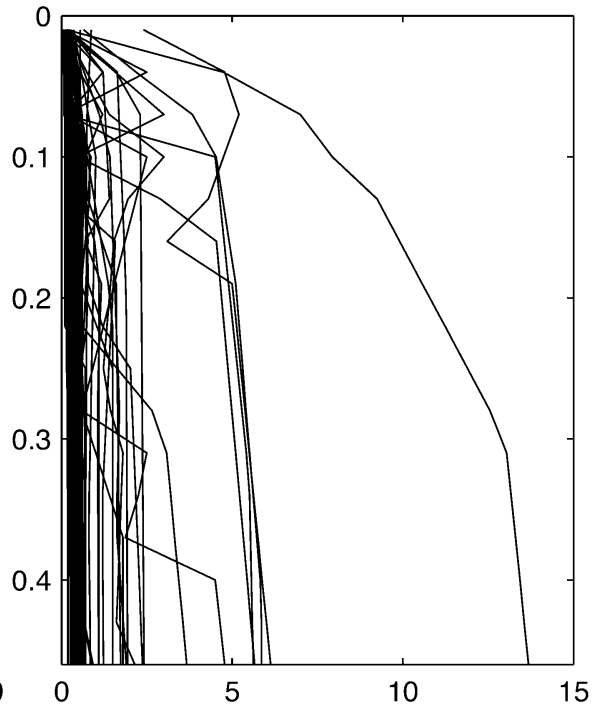

(d)

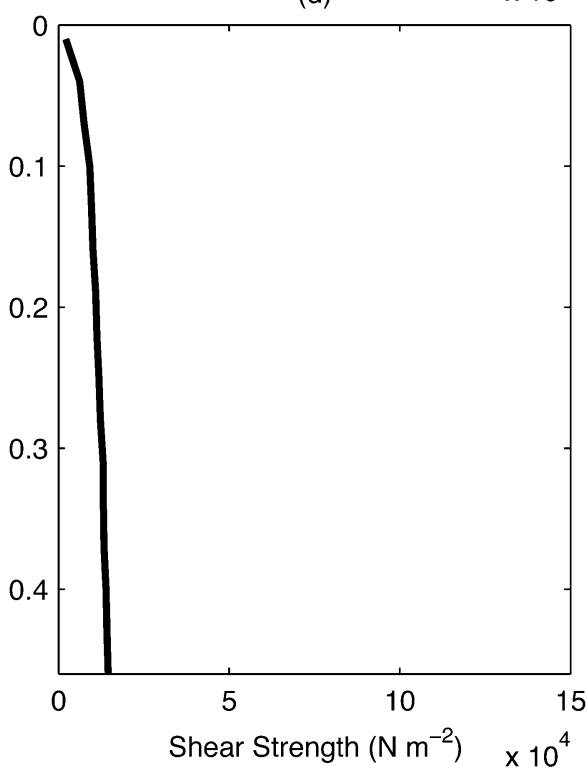

Fig. 11. Sediment density $\rho_{s}(z)$ and static shear strength $S(z)$ profiles in the Baltic Sea from the cores collected at 59 mine-impact sites during the mine-drop experiment in June 2003: (a) individual density profiles, (b) individual static shear strength profiles, (c) mean density profile, and (d) mean static shear strength profile (after [24]).

with near-zero mean and small standard deviation (STD) using IMPACT35 (fourth column), and non-Gaussian-type distributions with large STD using IMPACT28 (third column).

The total number of observational points at each time sample $N(t)$ is around 41 as $t<1.2 \mathrm{~s}$ and reduces quickly with time as $t>1.2 \mathrm{~s}$ Fig. 9(a), which indicates that the model verification is reliable for $t<1.2 \mathrm{~s}$. The added value of IMPACT35 is easily seen from Fig. 9. For example, the root-mean-square error (rmse) of COM prediction is much smaller when using IMPACT35 than IMPACT28 [Fig. 9(b) and (c)]. The STDs of the model errors for the COM prediction are also much lower when using IMPACT35 than IMPACT28 [Fig. 9(e) and (f)]. The rmse of orientation prediction is smaller when using IMPACT35 than IMPACT28 for $t<1 \mathrm{~s}$. When $t>1 \mathrm{~s}$, the rmse of $\psi_{2}$ is around half when using IMPACT35 than when using IMPACT28 [Fig. 9(d) and (g)].

\section{VERIFICATION OF IMPACT35 IN SEDIMENT}

The Baltic Sea experiment was conducted in June 2003 by the German Federal Armed Forces Underwater Acoustic and Marine Geophysics Research Institute (FWG, Kiel, Germany) [21] with the full-size optical mine (Fig. 10) which is allowed to free fall from the winch. Table II shows the physical parameters of the optical mine. Table III lists the physical environments in the Baltic Sea. The full-size optical mine was released 59 times. The water depths of the drop sites were between 25.0 and $26.5 \mathrm{~m}$ (Fig. 11). The volume of mine burial percentage was measured. The readers are referred to [6] for detailed information.

After running IMPACT35 with the delta method for the sediment resistance (14) for each gravity core regime $\left[\rho_{s}(z), S(z)\right]$, the predicted and observed burial volumes (in percent) were compared (Fig. 12). The bias (mean predicted minus observed 


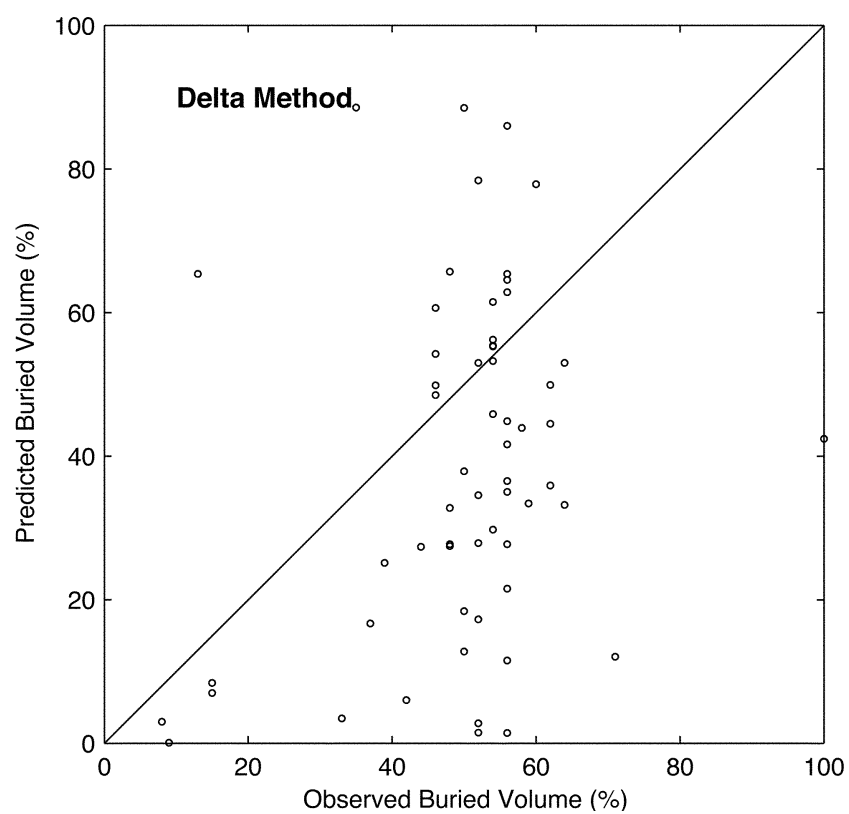

Fig. 12. Scatter diagrams of buried volume prediction against the Baltic Sea experimental data. Here, IMPACT35 uses the delta method for sediment resistance.

values) and rmse of burial volume are $11 \%$ and $26.8 \%$. The correlation coefficient between predicted and observed burial volumes is $0.374 \%$.

The histograms of the burial volume (in percent) are very different between the Baltic Sea experiment and the model prediction of IMPACT35 using the delta method [Fig. 13(a) and (b)]. In the experiment, the probability density function (pdf) has a peak at burial volume of $50 \%$ with a frequency of 26 . However, the model predicted pdf has a peak at $30 \%$ with a frequency of 11 .

\section{BEARING FACTOR METHOD}

A new (bearing factor) method is presented for calculating the sediment resistant force and torque.

\section{A. Sediment Resistance}

When the mine impacts and penetrates into the sediment, it creates a large transient pore pressure in the sediment that causes ruptures in the sediment and influences the resistance force on the cylinder [22], [23]. The resistance of the sediment to the mine's penetration is assumed to have the following three components: buoyancy force $\mathbf{F}_{b}^{s}$, hydrodynamic (drag and lift) force $\mathbf{F}_{h}^{s}$ (similar to air and water), and shear resistance force $\mathbf{F}_{r}^{S}$ (resistance to the rupture)

$$
\mathbf{F}^{s}=\mathbf{F}_{b}^{s}+\mathbf{F}_{h}^{s}+\mathbf{F}_{r}^{s} .
$$

The sediment buoyancy force per unit area is defined by

$$
\mathbf{F}_{b}^{s}=-\mathbf{n} \int_{z}^{z_{w s}} \rho_{s}\left(z^{\prime}\right) g d z^{\prime}
$$

where $\rho_{s}(z)$ is the sediment wet density (usually obtained from the sediment data), $\mathbf{n}$ is a unit vector normal to the mine surface

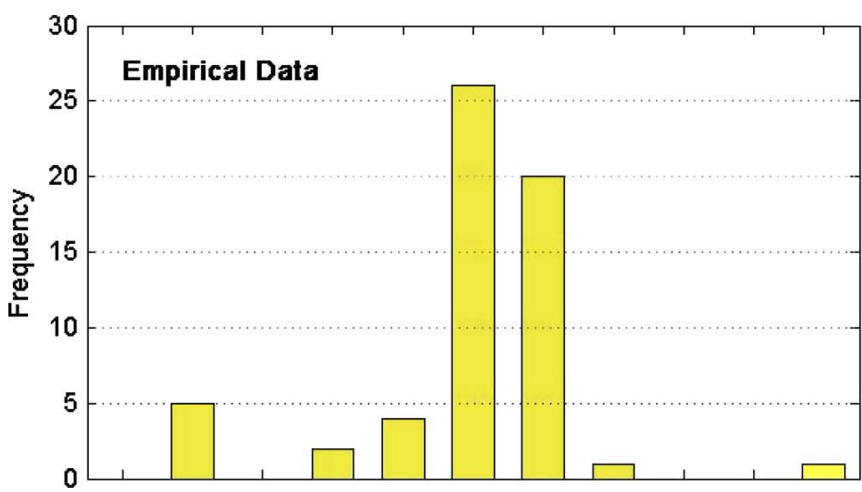

(a)

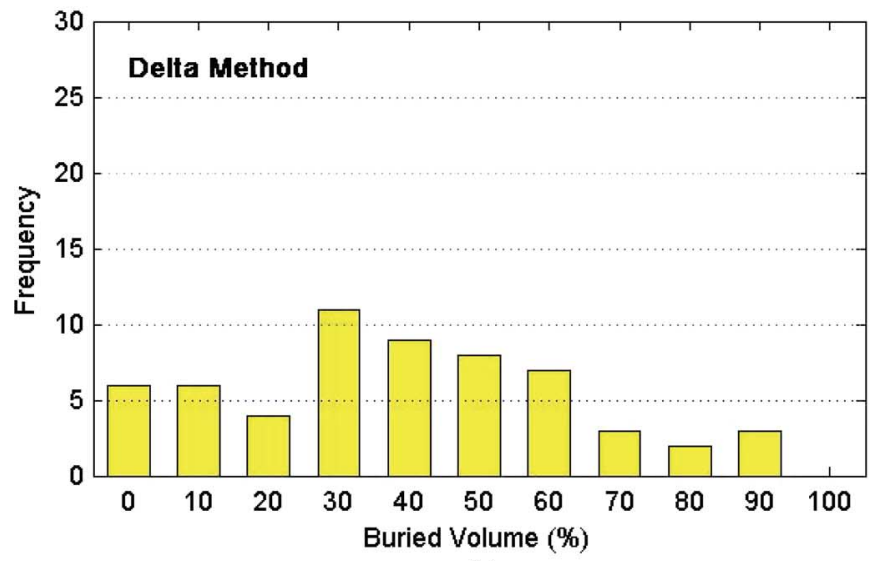

(b)

Fig. 13. Histograms of buried volume (in percent) from (a) Baltic Sea experiment and (b) prediction using IMPACT35 with the delta method.

(outward positive), and $z_{w s}$ represents the vertical coordinate of the water-sediment interface.

The shear resistance force $\left(\mathbf{F}_{r}^{S}\right)$ is in the opposite direction of $\mathbf{v}$ and acts on the mine. Its magnitude is proportional to the product of the sediment shear strength $(S)$ and the rupture area ( $A$, projection of sediment-contacting area perpendicular to the velocity $\mathbf{V}$ ) with a nonnegative bearing factor $N$ [15]

$$
\mathbf{F}_{r}^{s}=-\boldsymbol{\tau} N(p, v) S A, \quad N \geq 0 .
$$

The sediment resistance torque includes the hydrodynamic and shearing resistance torques

$$
\mathbf{M}^{s}=\mathbf{r} \times\left(\mathbf{F}_{r}^{s}+\mathbf{F}_{h}^{s}\right)=-[N(p, v) S A] \mathbf{r} \times \boldsymbol{\tau}+\mathbf{r} \times \mathbf{F}_{h}^{s} .
$$

Here, $p$ is the nondimensional penetration depth scaled by the diameter of the cylinder $(2 R)$. The sediment density in (23) and shear strength $(S)$ in (24) and (25) are measured.

The bearing factor increases with $p$ and decreases with the decreasing speed

$$
N(p, v)=\left[\mu_{1} p^{\mu_{2}}\right]\left[1+\lambda \log \left(\frac{v}{v_{\text {cri }}}\right)\right]
$$

where $\lambda$ is the $v$-effect parameter, $\left(\mu_{1}, \mu_{2}\right)$ are the $p$-effect parameters [15], and $v_{\text {cri }}$ is the critical speed. The bearing factor $N$ is amplified $\left[1+\lambda \log \left(v / v_{\text {cri }}\right)>1\right]$ for $v>v_{\text {cri }}$, independent of $v$ for $v=v_{\text {cri }}$, and is reduced $\left[1+\lambda \log \left(v / v_{\text {cri }}\right)<1\right]$ for $v<v_{\text {cri }}$. During the penetration, $v$ decreases since the 

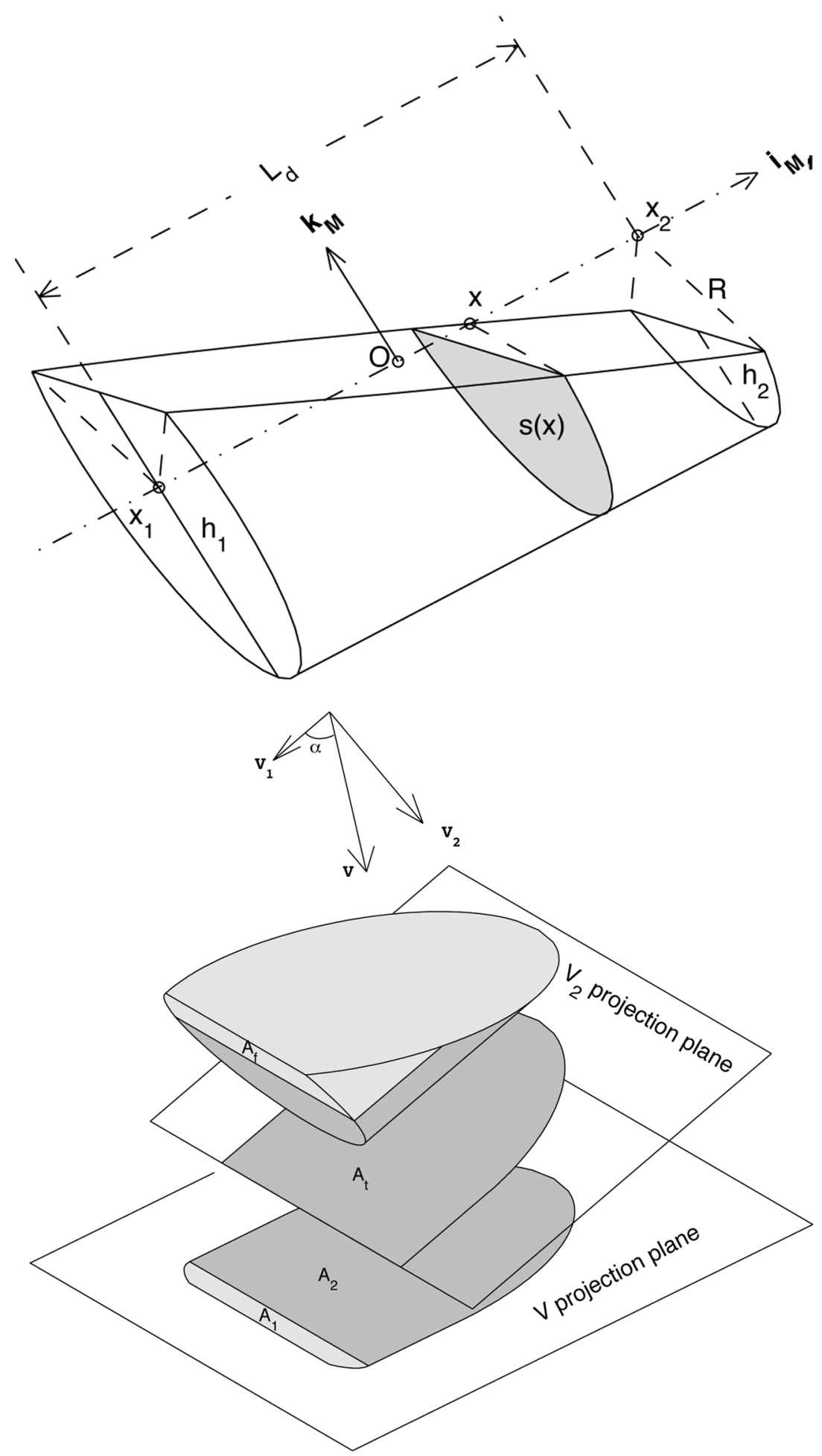

Fig. 14. Calculation of immersed area (after [12]).

buoyancy, hydrodynamic, and shear resistance forces oppose the penetration. Decrease of $v$ reduces bearing factor $N$. The two $p$-effect parameters are given by [15]

$$
\mu_{1}=9.3 \quad \mu_{2}=0.7 \text {. }
$$

Note that the nondimensional (26) and the two $p$-effect parameters are derived from a small probe under axial impact condi-
tion.Validity of the bearing factor method to mine-impact burial needs thorough evaluation.

Since $N$ cannot be negative, when $v$ decreases to a critical

$$
v=v_{\text {cri }} e^{-(1 / \lambda)}
$$

the bearing factor $N(p, v)$ and in turn the shearing resistance force become zero. The mine ceases the penetration in sediment. 
Note that $\lambda$ and $v_{\text {cri }}$ are the two tuning parameters of the numerical model. In this paper, we use

$$
\lambda=0.2 \quad v_{\text {cri }}=0.0015 \mathrm{~m} \mathrm{~s}^{-1} .
$$

\section{B. Rupture Area}

Usually, after passing through the water column, the cylinder's velocity reduces. The rupture area can be represented approximately by the contact surface area. Let $\left(A_{f}, A_{t}\right)$ be the sediment-contacting areas on the circular bottom (fan shape) and side (curved trapezoid). The rupture area $A$ is the summation of the projections of $\left(A_{f}, A_{t}\right)$ on the plane perpendicular to the mine's velocity $\mathbf{V}$

$$
A=A_{1}+A_{2} \quad A_{1}=A_{f} \cos \alpha \quad A_{2}=A_{t} \sin \alpha
$$

where $\alpha$ is the angle between $\mathbf{V}$ and the mine's axis. Let $R$ be the radius of the cylinder, $h$ be the depth of $A_{f}$, and $\left(h_{1}, h_{2}\right)$ be the depths of the trapezoid $A_{t}$ immersed in the sediment (Fig. 14). Let the length of the trapezoid be $L_{t} . A_{f}$ is computed simply by

$A_{f}=\frac{\theta}{2} R^{2}-(R-h) \sqrt{R^{2}-(R-h)^{2}}, \quad \theta=\cos ^{-1}\left(\frac{R-h}{R}\right)$.

$A_{t}$ is computed by

$$
A_{t}=\left\{\begin{array}{cc}
2 L_{t} R, & \text { for } h_{1}>h_{2} \geq R \\
\frac{L_{t}}{\left(h_{1}-h_{2}\right)}\left[R^{2}\left(\theta_{1}-\theta_{2}\right)\right. & \\
\left.-\left(R-h_{1}\right) b_{1}+\left(R-h_{2}\right) b_{2}\right], & \text { for } h_{2}<h_{1} \leq R \\
2 L_{t 1} R+\frac{L_{t 2}}{\left(R-h_{2}\right)} & \\
\quad \times\left[R^{2}\left(\frac{\pi}{2}-\theta_{2}\right)+\left(R-h_{2}\right) b_{2}\right], & \text { for } h_{1}>R>h_{2} \\
&
\end{array}\right.
$$

where $\left(L_{t 1}, L_{t 2}\right)$ are the lengths of subcylinders with $(h>$ $R, h<R)$ and $b_{1}$ and $b_{2}$ are computed by

$$
b_{1}=\sqrt{R^{2}-\left(R-h_{1}\right)^{2}}, \quad b_{2}=\sqrt{R^{2}-\left(R-h_{2}\right)^{2}} .
$$

\section{Model Improvement Using the BeARING FACTOR METHOD}

Model improvement is evaluated using the Baltic Sea experiment data. Similar to the process described in Section V, the modeled (with the bearing factor method) and observed burial volumes (in percent) were compared (Fig. 15). As evident, the sediment resistance using the bearing factor method improves the prediction capability of IMPACT35. The bias (mean predicted minus observed values) and rmse of the burial volume reduce to $0.1 \%$ and $15.8 \%$. The correlation coefficient between observed and predicted burial volumes increases to 0.435 (using the bearing factor method) from 0.374 (using the delta method).

The histogram of the predicted burial volume (in percent) using the bearing factor method (Fig. 16) is closer to that of

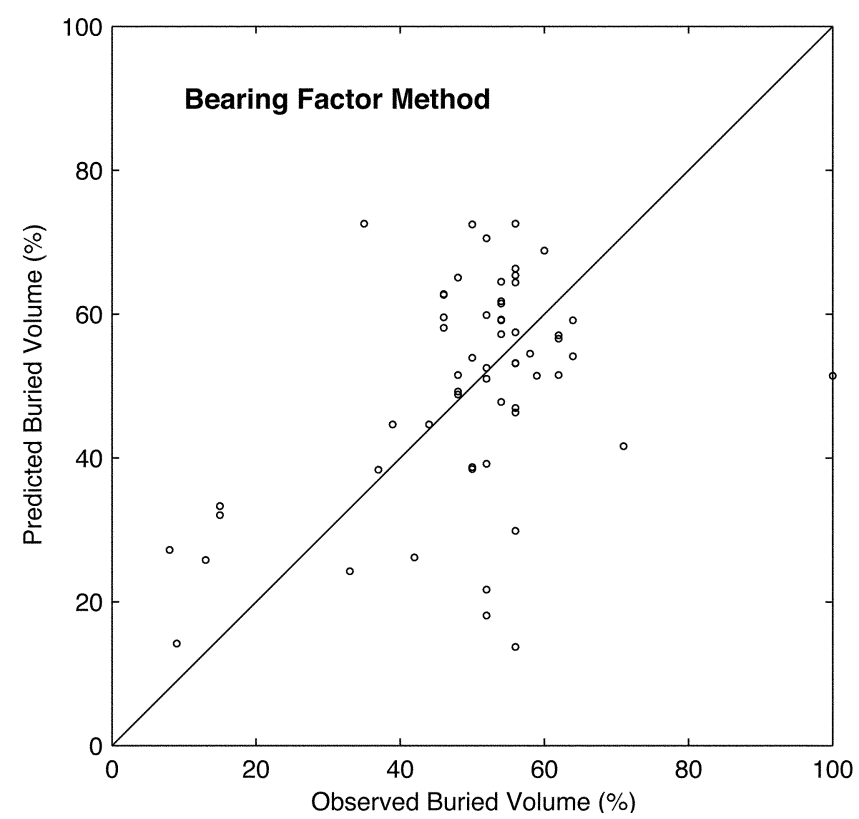

Fig. 15. Scatter diagrams of buried volume prediction against the Baltic Sea Experiment data. Here, IMPACT35 uses the bearing factor method for sediment resistance.

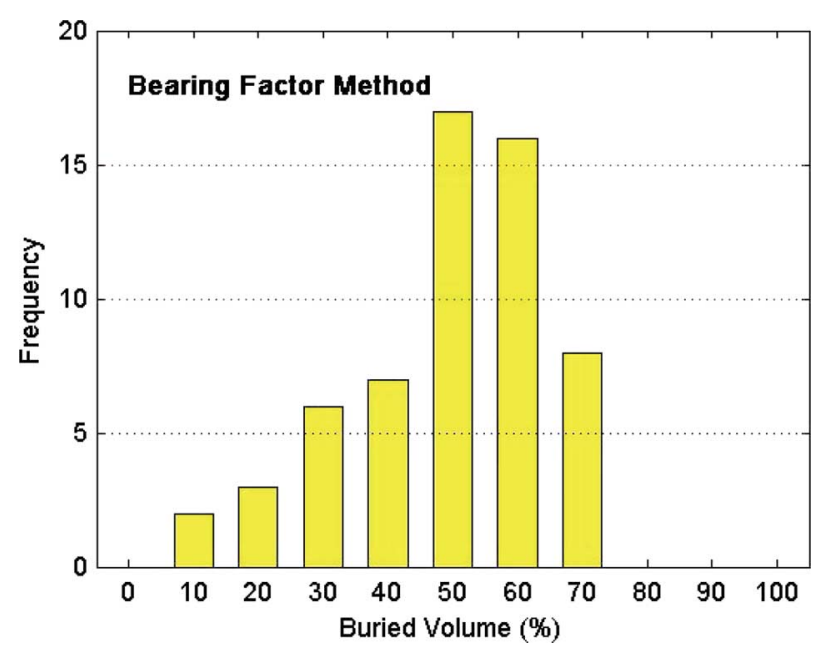

Fig. 16. Histogram of buried volume (in percent) prediction using IMPACT35 with the delta method.

the Baltic Sea experiment [Fig. 13(a)] than the histogram of the predicted burial volume (in percent) using the delta method Fig. 13(b). In the experiment, the histogram has a peak at burial volume of $50 \%$ with a frequency of 26 . In the prediction, the histogram has a peak at $30 \%$ with a frequency of 11 using the delta method Fig. 13(b). However, the histogram has a peak at $50 \%$ with a frequency of 17 (Fig. 16).

The histogram of the model error is more symmetric around the zero error using the bearing factor method than using the delta method. For example, the histogram has a peak at zero error with frequency of 16 using the bearing factor method [Fig. 17(b)], and a peak at $-10 \%$ error with the frequency of 12 using the delta method [Fig. 17(a)]. The burial volume prediction is unbiased using the bearing factor method, and negatively biased using the delta method. 


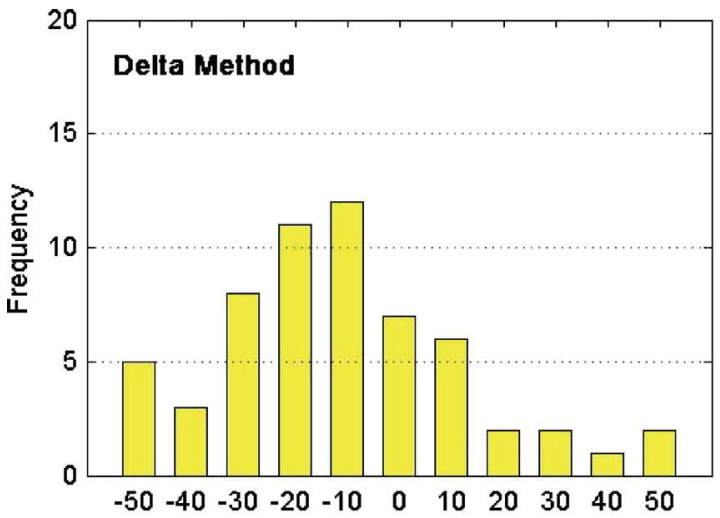

(a)

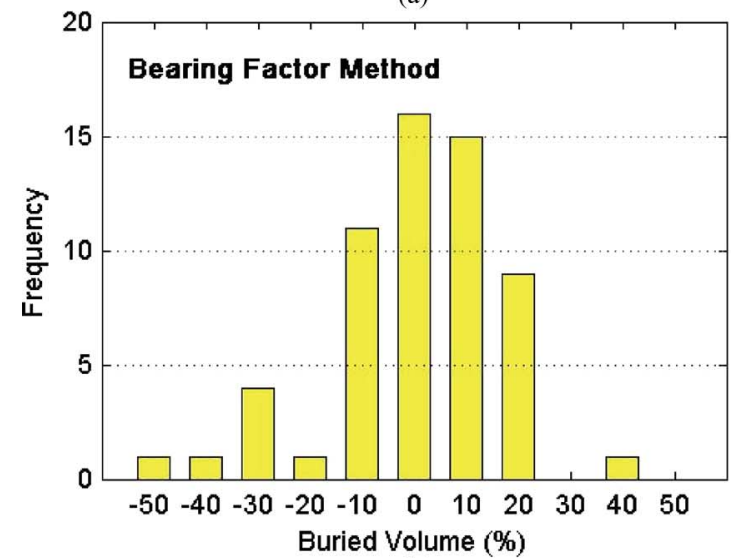

(b)

Fig. 17. Histograms of the buried volume prediction error of IMPACT35 using (a) the delta method, and (b) the bearing factor method.

\section{SUMMARY}

The following points summarize this paper.

1) The 3-D mine-impact burial prediction model (IMPACT35) was recently developed to predict the translation and orientation of falling cylindrical mine through air, water, and sediment. It contains the following three components: triple coordinate transform, cylinder decomposition, and hydrodynamics of falling rigid object in a single medium (air, water, or sediment) and in multiple media (air-water and water-sediment interfaces).

2) Data collected from two mine-impact burial experiments were used to verify the existing IMPACT35. The predicted mine track and orientation in the water column agree quite well with the NSWC-Caderock data. The rmse of the mine's position and orientation is much smaller using IMPACT35 than using IMPACT28. However, the predicted mine burial volume in the sediment was not as good as the mine trajectory in the water column.

3) Calculation of the sediment resistant force and torque is updated from the delta method (old) to the bearing factor method (new). With the bearing factor method, the prediction capability of IMPACT35 has been greatly improved. The prediction error satisfies near-Gaussian distribution. The bias of the burial volume (in percent) prediction reduces from $11 \%$ using the delta method (old) to $0.1 \%$ using the bearing factor method. Correspondingly, the rmse reduces from $26.8 \%$ to $15.8 \%$.

4) IMPACT35 developed in this paper is for cylindrical mines only. It is necessary to extend the modeling effort to more realistic mine shapes such as Rockan and Manta for operational use.

\section{ACKNOWLEDGMENT}

The authors would like to thank Dr. P. Valent and Dr. A. Abelev at the NRL for providing the NSWC-Carderock experiment data, Dr. T. Weaver at the FWG for providing the Baltic Sea experiment data, and the two anonymous reviewers and the editor Dr. M. D. Richardson for comments that improved the manuscript greatly.

\section{REFERENCES}

[1] J. M. Boorda, Mine Countermeasures-An Integral Part of Our Strategy and Our Forces. Washington, DC: Federation of American Scientists, 1999 [Online]. Available: http://www.fas.org/man/dod101/sys/ship/weaps/docs/cnopaper.htm

[2] S. A. Jenkins, D. L. Inman, M. D. Richardson, T. F. Wever, and J. Wasyl, "Scour and burial mechanisms of objects in the nearshore," IEEE J. Ocean. Eng., vol. 32, no. 1, pp. 78-90, Jan. 2007.

[3] S. E. Rennie, A. Brandt, and N. Plant, "A probabilistic expert system approach for sea mine burial prediction," IEEE J. Ocean. Eng., vol. 32, no. 1, pp. 260-272, Jan. 2007.

[4] S. Haeger, "Operational ocean modeling support for mine warfare in operation Iraqi freedom," in Proc. 6th Int. Symp. Technol. Mine Problem, Monterey, CA, May 10-13, 2004, DVD-ROM.

[5] P. Fleischer, "Mine burial prediction NAVOCEANO perspective," presented at the 5th Annu. ONR Workshop Mine Burial Prediction, Kona, HI, Jan. 31-Feb. 22005

[6] P. A. Elmore, M. D. Richardson, and R. H. Wilkens, "Exercising the Monte Carlo mine burial prediction system for impact and scour burial for operational Navy use," IEEE J. Ocean. Eng., vol. 32, no. 1, pp. 273-283, Jan. 2007.

[7] T. B. Smith, "Validation of the mine impact burial model using experimental data," M.S. thesis, Dept. Oceanogr., Naval Postgrad. School, Monterey, CA, 2000.

[8] P. C. Chu, C. W. Fan, A. D. Evans, and A. F. Gilles, "Triple coordinate transforms for prediction of falling cylinder through the water column," J. Appl. Mech., vol. 71, pp. 292-298, 2004.

[9] P. C. Chu, A. F. Gilles, C. W. Fan, J. Lan, and P. Fleischer, "Hydrodynamics of falling cylinder in water column," Adv. Fluid Mech., vol. 4, pp. $163-181,2002$.

[10] P. C. Chu, A. F. Gilles, C. W. Fan, and P. Fleischer, "Hydrodynamics of falling mine in water column," in Proc. 4th Int. Symp. Technol. Mine Problem, 2000, CD-ROM.

[11] P. C. Chu and C. W. Fan, "Pseudo-cylinder parameterization for mine impact burial prediction," J. Fluids Eng., vol. 127, pp. 1515-1520, 2005.

[12] P. C. Chu and C. W. Fan, "Prediction of falling cylinder through airwater-sediment columns," J. Appl. Mech., vol. 73, pp. 300-314, 2006.

[13] P. C. Chu, A. F. Gilles, and C. W. Fan, "Experiment of falling cylinder through the water column," Exp. Thermal Fluid Sci., vol. 29, pp. $555-568,2005$.

[14] A. Evans, "Hydrodynamics of mine impact burial," M.S. thesis, Dept. Oceanogr., Naval Postgrad. School, Monterey, CA, 2002.

[15] C. P. Aubeny and H. Shi, "Effect of rate-dependent soil strength on cylinders penetrating into soft clay," IEEE J. Ocean. Eng., vol. 32, no. 1, pp. 49-56, Jan. 2007.

[16] P. C. Chu, C. W. Fan, and A. D. Evans, "Three-dimensional rigid body impact burial model (IMPACT35)," Adv. Fluid Mech., vol. 6, pp. 43-52, 2004.

[17] P. C. Chu, A. Evans, T. Gilles, T. Smith, and V. Taber, "Development of Navy's 3D mine impact burial prediction model (IMPACT35)," in Proc. 6th Int. Symp. Technol. Mine Problem, Monterey, CA, 2004, DVD-ROM.

[18] P. C. Chu, C. Allen, and P. Fleischer, "Non-cylindrical mine impact experiment," in Proc. 7th Int. Symp. Technol. Mine Problem, Monterey, CA, 2006, DVD-ROM. 
[19] A. V. Abelev, P. J. Valent, and K. T. Holland, "Behavior of a large cylinder in free fall through water," IEEE J. Ocean. Eng., vol. 32, no. 1, pp. 10-20, Jan. 2007.

[20] K. T. Holland, A. W. Green, A. Abelev, and P. J. Valent, "Parameterization of the in-water motions of falling cylinders using high-speed video," Exp. Fluids, vol. 37, pp. 690-770, 2004, doi: 10.1007/800348004-0859-2.

[21] P. A. Elmore, R. Wilkens, T. Weaver, and M. D. Richardson, "IMPACT 28 and 35 simulations of 2003 Baltic Sea cruise: Model results and comparison with data," presented at the 5th Annu. ONR Workshop Mine Burial Prediction, Kona, HI, Jan. 31- Feb. 22005.

[22] A. Palmer, "Speed effect in cutting and ploughing," Geotechnique, vol. 49, no. 3, pp. 285-294, 1997.

[23] B. C. Simonsen and N. E. O. Hansen, "Protection of marine structures by artificial islands," in Ship Collision Analysis, Gluver and Olsen, Eds. Rotterdam, The Netherlands: Balkema, 1998, pp. 201-215, ISBN: 9054109629.

[24] T. Wever, "Surprising mine burial observations at MVCO," presented at the 5th Annu. ONR Workshop Mine Burial Prediction, Kona, HI, Jan. 31- Feb. 22005.

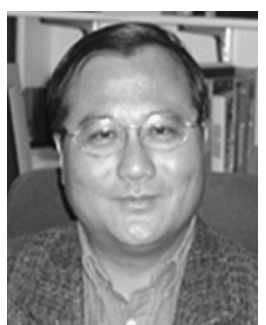

Peter C. Chu received the Ph.D. degree in geophysical fluid dynamics from the University of Chicago, Chicago, IL, in 1985.

$\mathrm{He}$ is a Professor of Oceanography and Head of the Naval Ocean Analysis and Prediction (NOAP) Laboratory, the Naval Postgraduate School, Monterey, CA. His research interests include ocean analysis and prediction, coastal modeling, littoral zone oceanography for mine warfare, mine-impact burial prediction, mine acoustic detection, and satellite data assimilation for undersea warfare.

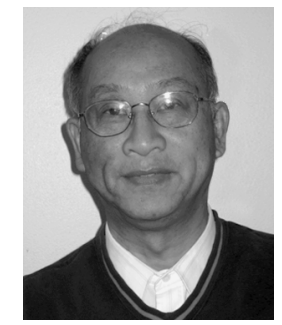

Chenwu Fan received the M.S. degree in mechanic engineering from China Textile University, Shanghai, China, in 1982.

$\mathrm{He}$ is an Oceanographer at the Naval Postgraduate School, Monterey, CA. His research interests include numerical simulation, ocean analysis and prediction, coastal modeling, littoral zone oceanography for mine warfare, and mine-impact burial prediction. 